\title{
ANÁLISE DE ANTOCIANINAS E CAROTENOIDES DA PIMENTA VERMELHA DEDO-DE-MOÇA (Capsicum baccatum var. pendulum) SOB DIFERENTES CONDIÇÕES DE ARMAZENAMENTO E PROCESSAMENTO
}

\author{
A. S. GRAZIOLI ${ }^{1}$, G. S. da ROSA ${ }^{2}$ \\ ${ }^{1}$ Universidade Federal do Pampa - UNIPAMPA, Discente da Engenharia Química \\ ${ }^{2}$ Universidade Federal do Pampa - UNIPAMPA, Docente da Engenharia Química \\ E-mail para contato: andersongrazioli@live.com
}

\begin{abstract}
RESUMO - A pimenta vermelha dedo-de-moça é uma das pimentas mais famosas no Brasil. Cultivada principalmente nos estados de São Paulo e Rio Grande do Sul, é apreciada por seu aroma suave e pungência leve, sendo consumida na forma de molho líquido e em conserva. Há, na sua estrutura celular, a presença de antocianinas e carotenoides, que são compostos bioativos antioxidantes. O objetivo deste trabalho foi analisar as quantidades de antocianinas e carotenoides presentes na pimenta vermelha dedo-de-moça in natura, verificando a influência de diferentes técnicas de armazenamento (refrigerada e congelada) e processamento (liofilização) no conteúdo desses compostos. As pimentas foram selecionadas e processadas em moinho analítico. Para a extração das antocianinas, foi utilizado o método de Fuleki e Francis (1968), que utiliza etanol acidificado como solvente para romper a membrana celular e dissolver os pigmentos. Para os carotenoides, fez-se o uso do método desenvolvido por Rodriguez-Amaya (1999), em que a extração é realizada com acetona. Foram efetuadas análises de umidade das amostras in natura e liofilizada, utilizando o método da estufa a $105{ }^{\circ} \mathrm{C}$ por $24 \mathrm{~h}$. A umidade da pimenta in natura foi de $86,3 \%$ e da amostra liofilizada foi de 16,9 \%, ambas em base úmida. A maior quantidade encontrada de antocianinas e carotenoides totais foi na amostra refrigerada. Porém, a liofilizada se torna mais adequada por apresentar menor quantidade de água, assim conservando esses compostos por maior período de tempo.
\end{abstract}

\section{INTRODUÇÃO}

As pimentas (Capsicum spp.) compõem uma importante parte do mercado de hortaliças frescas do Brasil, e também do segmento de condimentos, temperos e conservas, a nível mundial (Costa et al., 2008). Frutas Capsicum são ricas fontes de antioxidantes e compostos benéficos para a saúde humana: carotenoides, vitaminas $\mathrm{C}$, vitamina $\mathrm{E}$, flavonoides (compostos fenólicos, como as antocianinas) e capsaicinas (Golubikna et al., 2014). Segundo Kappel (2007), os níveis destes compostos podem variar devido ao genótipo e maturação da mesma. Os compostos bioativos são considerados como potentes antioxidantes, sendo que estes possuem a importante função de neutralizar os radicais livres no organismo humano, reduzindo assim o risco de 


\section{9 a 22 de outubro de 2014 \\ Florianópolis/SC}

doenças tais como artrite, doenças cardiovasculares doenças e câncer, além de retardar o processo de envelhecimento (Faustino et al., 2007).

As antocianinas são pigmentos que geralmente, a cor varia do vermelho ao azul, cita Gomes (2010). Além disso, podem ser utilizadas como corante natural em substituição aos sintéticos (Caneda e Rosa, 2013). Um dos traços mais característicos das pimentas Capsicum, é sua diversidade em cores de frutas, que é devido a um teor de notável em diferentes carotenoides (Burruezo et al., 2010). A sua coloração vai de amarelo a vermelho, sendo que estes pigmentos, essenciais para o uso como corantes alimentares, também conferem a esses frutos um notável valor nutricional. Assim, muitos carotenoides encontrados em pimentas mostraram uma forte atividade antioxidante (Matsufuji et al., 1998).

De acordo com a literatura da área sabe-se que os compostos antioxidantes caracterizam-se por serem instáveis e susceptíveis à degradação, dependendo das condições em que a matériaprima é submetida. A liofilização é um processo de secagem capaz de remover a água dos produtos através da sublimação, em que o material congelado é submetido a baixas pressões, proporcionando a eliminação da água contida no produto direto da forma sólida para a gasosa (Mujumdar, 2006). A técnica tem como objetivo conservar os compostos presentes na matériaprima, diminuindo a água presente, e possibilitando a estabilização do produto por um maior período de tempo.

Devido a isso, o objetivo deste trabalho foi determinar o conteúdo de antocianinas e carotenoides presentes na pimenta vermelha dedo-de-moça (Capsicum baccatum var. pendulum) in natura, e avaliar a influência de diferentes técnicas de armazenamento (refrigeração e congelamento) e processamento (liofilização) no conteúdo desses compostos bioativos.

\section{MATERIAIS E MÉTODOS}

\subsection{Matéria-prima}

As pimentas vermelhas da espécie Capsicum baccatum var. pendulum utilizadas nos experimentos, foram adquiridas no mercado local da cidade de Bagé, situada no estado do Rio Grande do Sul. O local de realização dos experimentos foi no laboratório de Engenharia Química da Universidade Federal do Pampa (UNIPAMPA), campus Bagé. Para os experimentos realizados neste trabalho foram retiradas as sementes e o pedúnculo das pimentas, trabalhando-se apenas com a polpa desta matéria-prima processada em moinho analítico.

\subsection{Equipamento Experimental}

Para o armazenamento das amostras sob refrigeração e congelamento foram utilizados um refrigerador com freezer (Electrolux, modelo Super Freezer DC47A). Para o processo de secagem por liofilização, foi utilizado o liofilizador (Terroni, modelo LS3000) conforme apresentado na Figura 1. 


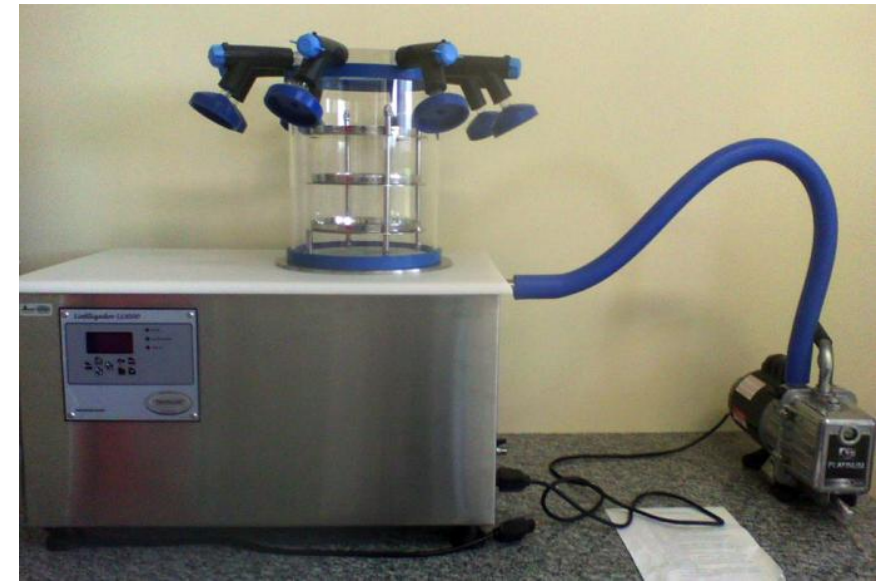

Figura 1 - Liofilizador.

Para a realização das análises de conteúdo de antocianinas e carotenoides totais, foi utilizado um espectrofotômetro UV visível (Equilam, modelo UV755B), conforme Figura 2.

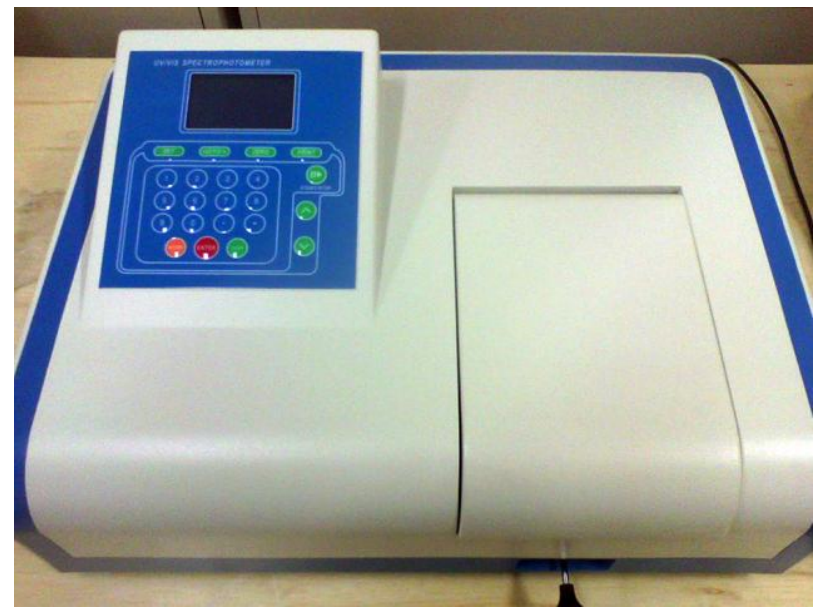

Figura 2 - Espectrofotômetro UV-Visível.

\subsection{Procedimento Experimental}

O conteúdo de umidade da polpa foi analisado em triplicatas através do método em estufa, a $105{ }^{\circ} \mathrm{C}$ por $24 \mathrm{~h}$ (AOAC, 1995) para a amostra in natura, congelada e seca por liofilização.

As análises quantitativas do conteúdo de antocianinas e carotenoides totais nas amostras foram realizadas em triplicatas, em que se determinou o conteúdo destes compostos bioativos na amostra in natura e nas amostras submetidas às diferentes condições de armazenamento e processamento: refrigerada (28 dias), congelada (28 dias) e liofilizada. 
Secagem por liofilização: A polpa da pimenta vermelha foi previamente submetida à etapa de congelamento, na temperatura de $-20{ }^{\circ} \mathrm{C}$ por um período de 28 dias. Após, as amostras foram levadas ao liofilizador, onde ficaram por $48 \mathrm{~h}$ submetidas a uma pressão de $174 \mu \mathrm{Hg}$ de vácuo e a temperatura de $-48{ }^{\circ} \mathrm{C}$. Ao final deste processamento as amostras foram caracterizadas.

Conteúdo de antocianinas totais: A determinação foi feita pelo método de Fuleki e Francis (1968) adaptado. Para o preparo da amostra, pedaços cortados longitudinalmente de pimenta foram levados ao moinho analítico para o processamento da polpa (Figura 3), assim mantendo um padrão para as amostras. Depois foi pesado $1 \mathrm{~g}$ de amostra em um béquer e adicionado 25 $\mathrm{mL}$ de etanol acidificado com ácido clorídrico $(\mathrm{pH} 1)$ para a etapa de extração. A amostra ficou em repouso durante $1 \mathrm{~h}$, homogeneizando a cada $5 \mathrm{~min}$. Em seguida, o conteúdo foi filtrado à vácuo e completado o volume com o etanol em um balão volumétrico de $50 \mathrm{~mL}$. A leitura a absorbância foi realizada no espectrofotômetro a $520 \mathrm{~nm}$, usando o etanol acidificado como branco.

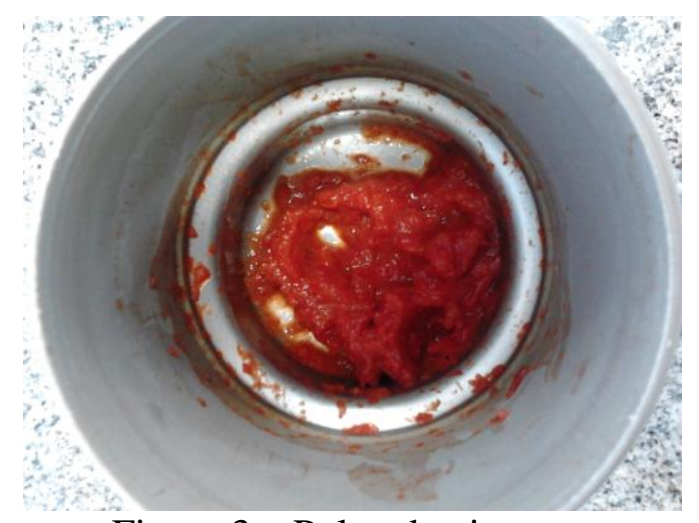

Figura 3 - Polpa da pimenta.

O conteúdo de antocianinas totais ( $A n t_{\text {totais }}$ ) foi calculado através Equação 1, que segundo Teixeira, Stringheta e Oliveira (2003), o resultado se expressa em $\mathrm{mg}$ de cianidina-3glicosídeo. $100 \mathrm{~g}^{-1}$ de amostra avaliada.

$$
\text { Ant }_{\text {totais }}=\frac{A \times V_{E} \times 1000}{m \times E_{1 c m}^{1 \% 6}}
$$

em que A é a absorbância do extrato, $V_{E}$ é volume do extrato em $\mathrm{mL}, m$ é a massa da amostra em gramas, 1000 é o fator de correção para que o resultado seja expresso em $100 \mathrm{~g}$ de amostra e $E^{1 \%}{ }_{c m}$ é o coeficiente de extinção (982).

Conteúdo de carotenoides totais: O método utilizado foi o de Rodriguez-Amaya (1990) adaptado. Após a amostra ser processada, foram pesados $2 \mathrm{~g}$ de amostra e adicionado em um béquer $20 \mathrm{~mL}$ de acetona gelada $\left( \pm 4{ }^{\circ} \mathrm{C}\right)$ para a extração dos compostos, homogeneizando a amostra durante 10 min. Em seguida, a amostra foi filtrada à vácuo e o filtrado transferido para 
um funil de separação, onde acrescentou-se $30 \mathrm{~mL}$ de éter de petróleo e $20 \mathrm{~mL}$ de água. O uso do éter de petróleo justifica-se devido os carotenoides serem lipossolúveis, enquanto que a água serve para remover algum resíduo de acetona que possa permanecer na fase oleosa. Após a mistura, foi descartada a fase inferior. Repete-se o procedimento de lavagem com água duas vezes, para remoção total da acetona. $\mathrm{O}$ extrato restante (superior) foi avolumado em balão volumétrico de $50 \mathrm{~mL}$, onde é completado o volume com o éter de petróleo. Em seguida, a amostra foi diluída $1 / 10$ e levada para a leitura da absorbância no espectrofotômetro a $450 \mathrm{~nm}$, usando o éter de petróleo como branco para calibração.

O conteúdo de carotenoides totais foi expresso em mg de $\beta$-caroteno. $100 \mathrm{~g}^{-1}$ de amostra avaliada, utilizando a Equação 2.

$$
C_{\text {totais }}=\frac{A \times V_{D} \times 50 \times 10^{6}}{V_{\text {aliq }} \times 2500 \times 100 \times m}
$$

em que $A$ é a absorbância do extrato, $50 \mathrm{~mL}$ é o volume utilizado, $m$ é a massa em $g$ da amostra utilizada, $V_{D}$ e $V_{\text {aliq }}$ é utilizado para diluição, sendo os demais fatores de correção para o valor ser expresso na unidade mencionada acima.

\section{RESULTADOS E DISCUSSÃO}

A Figura 4 apresenta as fotografias das amostras de pimenta vermelha in natura (a), liofilizada (b) e liofilizada após trituração em moinho analítico (c).

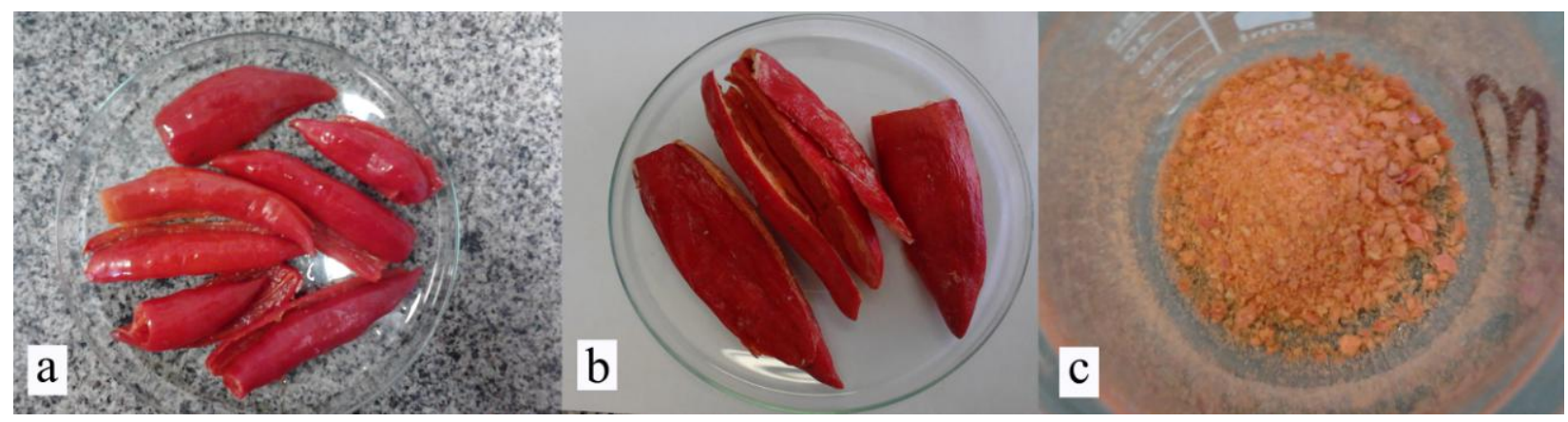

Figura 4 - Amostras: (a) in natura, (b) liofilizada, (c) liofilizada em pó.

A Tabela 1 apresenta os resultados do conteúdo de umidade das amostras da pimenta vermelha dedo-de-moça in natura, congelada e liofilizada. 
Tabela 1 - Umidade da Pimenta Analisada

\begin{tabular}{|c|c|}
\hline Amostra & Umidade \% (b.u.) * \\
\hline in natura & $86,30 \pm 0,54$ \\
\hline congelada & $86,93 \pm 0,34$ \\
\hline liofilizada & $16,90 \pm 0,28$ \\
\hline
\end{tabular}

*média \pm desvio médio $(n=3)$

Os resultados apresentados na Tabela 1 para a amostra in natura condizem com os apresentados na literatura. Caneda e Rosa (2013) reportaram conteúdo de umidade para a pimenta vermelha de 88, 31 \% (b.u.). Com relação ao conteúdo de umidade da amostra liofilizada, apesar do processo ter reduzido este conteúdo, o mesmo encontra-se acima da determinação da Agência da Vigilância Sanitária (ANVISA) que permite o teor de umidade máximo de $5 \%$ para produtos liofilizados (Resolução CNNPA $n^{\circ} 12$ ). Desta forma em trabalhos futuros pretende-se estudar diferentes condições para o processo de liofilização de forma a minimizar tal valor. De acordo com Moraes et al. (2012), a secagem por liofilização das frutas abacaxi, melão, maracujá, maracujá-do-mato, manga, tamarindo e resíduo de acerola, também proporcionaram conteúdos de umidade acima do indicado pela legislação (entre 8,60 e $27,68 \%$, b.u.).

Os valores de antocianinas e carotenoides totais, em base úmida, para a amostra in natura foram de 26,5 e 236,8 mg. $100 \mathrm{~g}^{-1}$, respectivamente. No trabalho de Caneda (2013) o conteúdo de antocianinas presentes na pimenta vermelha in natura foi de $22,7 \mathrm{mg} \cdot 100 \mathrm{~g}^{-1}$.

A Tabela 2 apresenta os resultados para as análises de conteúdo de antocianinas e carotenoides totais, em base seca, para as diferentes amostras.

Tabela 2 - Antocianinas e Carotenoides (Base seca)

\begin{tabular}{|c|c|c|c|c|}
\hline Amostra & $\begin{array}{c}\text { Antocianinas } \\
\text { (mg / 100 g s.s. })\end{array}$ & Variação (\%) & $\begin{array}{c}\text { Carotenoides } \\
(\mathrm{mg} / 100 \mathrm{~g} \text { s.s. })\end{array}$ & Variação (\%) \\
\hline & & & & \\
\hline in natura & $193,27 \pm 1,58$ & - & $1728,36 \pm 93,38$ & - \\
\hline Refrigerada & $239,48 \pm 8,99$ & $+23,9$ & $2153,96 \pm 24,41$ & $+24,6$ \\
\hline Congelada & $161,25 \pm 7,69$ & $-16,6$ & $1612,66 \pm 136,22$ & $-6,7$ \\
\hline Liofilizada & $142,33 \pm 4,73$ & $-26,4$ & $1211,33 \pm 59,38$ & $-29,9$ \\
\hline
\end{tabular}

*média \pm desvio médio( $n=3)$

Para as antocianinas e carotenoides totais foram observados comportamentos similares. A 


\section{9 a 22 de outubro de 2014 \\ Florianópolis/SC}

amostra submetida à refrigeração por um período de 28 dias apresentou um acréscimo do conteúdo de compostos bioativos, sendo este entre 23 e $24 \%$, para as antocianinas e carotenoides, respectivamente. Esses aumentos podem estar associados com a maturação da pimenta durante o período de armazenamento com refrigeração.

As amostras submetidas ao processo de congelamento e liofilização apresentaram perdas de antocianinas de 16,6 e 26,4 \%, respectivamente. Para os carotenoides totais, as perdas para as amostras congeladas e liofilizadas foram de 6,7 e 29,9\%, respectivamente. De acordo com estudos de estabilidade de compostos bioativos presentes na amora-preta frente ao armazenamento congelado realizado por Jacques (2009), observou-se que estes podem apresentar elevadas taxas de degradação.

Através dos resultados apresentados é possível inferir que tanto o armazenamento por congelamento quanto o processamento por liofilização proporcionam perdas para os compostos bioativos. As antocianinas foram mais afetadas no congelamento, enquanto que para a liofilização ambos compostos aqui analisados demonstraram-se sensíveis. Entretanto, os valores observados para o processamento utilizando a técnica de liofilização mostram que esta técnica de secagem apresenta vantagens com relação a manutenção dos compostos bioativos, uma vez que no estudo realizado por Caneda (2013) foram reportadas perdas de até $74 \%$ das antocianinas quando as amostras foram secas por secagem convectiva a ar quente na temperatura de $60{ }^{\circ} \mathrm{C}$.

\section{CONCLUSÃO}

As amostras da pimenta dedo-de-moça, em diferentes condições de armazenamento e processamento, tiveram as antocianinas e carotenoides totais quantificados através da extração desses compostos. A técnica de liofilização proporcionou a obtenção de um produto com conteúdo de umidade acima do exigido pela ANVISA para produtos liofilizados $(<5 \%$, b.u. $)$.

Observou-se que comparando a amostra in natura e a refrigerada, para antocianinas e carotenoides, houve um aumento na quantidade de compostos bioativos, mostrando que o ambiente em que foi condicionada a amostra favoreceu a maturação e a consequente liberação dos compostos analisados. Para as amostras congeladas e liofilizadas, tanto para antocianinas como carotenoides, foram observadas perdas, entretanto, estes valores de perdas foram inferiores aos valores reportados na literatura para a secagem convectiva da pimenta com ar quente.

\section{REFERÊNCIAS BIBLIOGRÁFICAS}

AOAC. Official Methods of Analysis, 16th Ed. c. 2, p. 4. Washington: Association of Official Analytical Chemists Inc. 1995.

BRASIL. Ministério da Saúde. Agência Nacional de Vigilância Sanitária (ANVISA). Resolução - CNNPA n.12, de 24/07/1978 - Dispõe sobre normas técnicas especiais. Disponível em: www.anvisa.gov.br. Acesso em 02 de maio de 2014.

BURRUEZO, A. R.; MAS, M. C. G., and NUEZ, F. Carotenoid Composition and Vitamin A 
Value in Ají (Capsicum baccatum L.) and Rocoto (C. pubescens R. \& P.), 2 Pepper Species from the Andean Region. Journal of Food Science, v. 75, n. 8, 2010.

CANEDA, C. M. Secagem da pimenta vermelha dedo-de-moça (Capsicum baccatum var. pendulum): compostos bioativos e propriedades antioxidantes. Trabalho de Conclusão de Curso, Universidade Federal do Pampa, Bagé, 2013.

CANEDA, C. M.; ROSA, G. S. Influência da operação de secagem no conteúdo de antocianinas da pimenta vermelha. X Congres. Bras. de Eng. Quím. Inic. Cient., p. 1-2. Vassouras-RJ, 2013.

COSTA, L. V.; LOPES, M. T. G.; LOPES, R. e ALVES, S. R. M. Polinização e fixação de frutos em Capsicum chinense Jacq.. Acta Amaz. 2008, v.38, n.2, p. 361-364.

FAUSTINO, J. M. F.; BARROCA, M. J.; GUINÉ, R. P. F. Study of the drying kinetics of green bell pepper and chemical characterization. Food and Bioproducts Processing, v. 85, n. C3, p. 163-170, 2007.

GOLUBKINA N.A., DZHOS E.A., PISHNAYA O.N., MAMEDOV M.I. e NADEZHKIN S.M., 2013. Biochemical Characteristics of Hot Pepper Fruit Grown in Moscow Region. Doklady Rossiiskoi Akademii Sel'skokhozyaistvennykh Nauk, 2013, n. 6, p. 24-27.

GOMES, S. M. C. Determinação de Antioxidantes por Cromatografia Líquida de Alta Pressão com Detecção Electroquímica. Dissertação de Mestrado da Universidade de Coimbra. 2010.

JACQUES, A. C., Estabilidade de compostos bioativos em polpa congelada de amora-preta (Rubus fruticosus). Dissertação de mestrado. Faculdade de Agronomia. Universidade Federal de Pelotas - Pelotas, 2009.

KAPPEL, V. D. (2007). Avaliação das propriedades antioxidantes e antimicrobiana de extrato de Capsicum baccatum L. var. pendulum. Universidade Federal do Rio Grande do Sul, Porto Alegre (dissertação de mestrado), 63 p.

MATSUFUJI H, HIROMICHI N., MAKOTO C., e MITSUHARU T. Antioxidant Activity of Capsanthin and the Fatty Acid Esters in Paprika (Capsicum annuum). J. Agric. Food Chem., p 1-2, v. 46, n. 9, Tokyo, 1998.

MORAES L. R. V, AZEVÊDO L. C. de, SANTOS V. M. L., LEITÃO T. J. V. Estudo comparativo da desidratação de frutas para fins de infusão, por método tradicional e liofilização. Revista Semiárido De Visu, v.2, n.2, p.254-264, 2012.

MUJUMDAR, A. S. Handbook of industrial drying. 3 ed. Ed. CRC Press, Nova York, 2006.

TEIXEIRA, L. N.; STRINGHETA, P. C.; OLIVEIRA, Fabiano Alves de. Comparação de métodos para quantificação de antocianinas. Revista Ceres, v. 55, n. 4, pg. 297-304, 2008. 